\title{
EXTRACCIÓN Y MEDIDA DE PEROXIDASA EN PULPA DE ARAZÁ (Eugenia stipitata MC Vaugh)
}

\author{
Carlos Eduardo Narváez-Cuenca
}

Departamento de Química, Facultad de Ciencias, Universidad Nacional de Colombia. Ciudad Universitaria, Bogotá-Colombia. Cra $30 N^{\circ} 45-03$

Recebido em 30/1/08; aceito em 20/6/08; publicado na web em 31/10/08

\begin{abstract}
EXTRACTION AND ACTIVITY OF PEROXIDASE IN ARAZÁ (Eugenia stipitata Mc Vaugh) PULP FRUIT. A technique for both extraction and activity measurement of peroxidase extracted from arazá (Eugenia stipitata Mc Vaugh) is described. Peroxidase from arazá pulp fruit was extracted using a combination of protein precipitation with acetone and extraction with $50 \mathrm{mM}$ sodium buffer phosphate ( $\mathrm{pH}$ 6.0). Optimum activity using guaiacol as $\mathrm{H}$-donor was obtained at $\mathrm{pH}$ from 5.0 to 6.5 , temperature from 60 to $75^{\circ} \mathrm{C}, \mathrm{H}_{2} \mathrm{O}_{2}$ between 10 to $15 \mathrm{mM}$ and guaiacol from 80 to $160 \mathrm{mM}$. Thermal inactivation showed a first-order inactivation kinetic. Reactivation was observed when extracts were heated at $80^{\circ} \mathrm{C}$ and afterwards incubated at $25^{\circ} \mathrm{C}$.
\end{abstract}

Keywords: blanching; frozen storage; inactivation.

\section{INTRODUCCIÓN}

El arazá (Eugenia stipitata Mc Vaugh) es un fruto proveniente de la Región Amazónica, tolerante a suelos ácidos y poco fértiles. Este fruto es conocido en algunas regiones como araçá boi. Por su elevada acidez el fruto entero no se destina al consumo, sino a la elaboración de productos como néctar, yogurt, entre otros. ${ }^{1}$

Diversos estudios coinciden con que el fruto de arazá tiene un tiempo de vida en anaquel relativamente corto. Así, cuando los frutos son cosechados en su madurez fisiológica y almacenados a $24{ }^{\circ} \mathrm{C}$, la madurez sensorial se presenta luego de 4 días. Después de 6 días hay un deterioro marcado en sus características. ${ }^{2}$ Cuando la temperatura de almacenamiento es de $18{ }^{\circ} \mathrm{C}$ la madurez sensorial ocurre luego de 5 días. ${ }^{1}$ Se ha encontrado que el fruto sufre daños por frío a temperaturas por debajo de $12{ }^{\circ} \mathrm{C},{ }^{1}$ por lo que se han propuesto algunas técnicas para aliviar estas alteraciones. Mediante el uso del choque térmico, en el que los frutos de arazá son calentados a $50{ }^{\circ} \mathrm{C}$ durante $30 \mathrm{~min}$ y posteriormente son refrigerados a $7^{\circ} \mathrm{C}$, se prolonga su vida útil hasta por 15 días y se evita la aparición de lesione por frío. ${ }^{2}$ La inmersión de los frutos en una solución de $\mathrm{CaCl}_{2} 4 \%(\mathrm{p} / \mathrm{v})$ previo a la refrigeración a $4{ }^{\circ} \mathrm{C}$ incrementa la firmeza y retrasa la maduración. Otro tratamiento que se reporta es el acondicionamiento a $20^{\circ} \mathrm{C}$ durante $18 \mathrm{~h}$ luego de la primera semana de refrigeración a $10^{\circ} \mathrm{C}$, con lo que se disminuyen las lesiones por frío y se prolonga la maduración, respecto a los frutos control. El uso de atmósferas modificadas también ha sido útil en el control de la maduración de los frutos de arazá. En frutos de arazá almacenados en bolsas de polietileno con una mezcla de $5 \% \mathrm{CO}_{2} \mathrm{y}$ $5 \%$ de $\mathrm{O}_{2}$ se prolonga la vida poscosecha en aproximadamente una semana respecto a los frutos control. ${ }^{1}$

La congelación de la pulpa de arazá es un método empleado para prolongar la calidad. ${ }^{3,4}$ Cuando la pulpa es congelada sin tratamiento previo su tiempo de vida útil se estima en un mes. ${ }^{3}$ El deterioro de la textura, la degradación del ácido ascórbico, el sabor metálico y fermentado causan deterioro que afecta la calidad de la pulpa durante la congelación. En trabajos anteriores se propone el escaldado de la pulpa en agua en ebullición a $92{ }^{\circ} \mathrm{C}$ durante 5 a 10 min, intervalo de tiempo durante el cual la temperatura en el centro de la pulpa llega entre 65 a $77^{\circ} \mathrm{C}$, respectivamente. Este tipo de tratamientos puede

e-mail: cenarvaezc@unal.edu.co constituirse en una herramienta útil para disminuir la velocidad de degradación del ácido ascórbico. ${ }^{4}$

La peroxidasa (POD, EC 1.11.1.7) ha sido ampliamente usada como indicadora de efectividad del escaldado por su alta tolerancia a tratamientos térmicos. Se espera que si la POD ha sido inactivada, las otras enzimas también. Además, es importante inactivar la POD debido a su vinculación con cambios en la coloración de frutas y hortalizas, degradación de compuestos fenólicos con importante valor antioxidante y pérdida de aroma. ${ }^{5,6}$ Cuando se usa esta enzima como indicadora, se espera que a un mayor grado de inactivación, la calidad se mantenga por un mayor tiempo. Sin embargo, se debe tener cuidado con este criterio, por cuanto aunque se garantice la inactivación enzimática, el tratamiento puede ser tan intenso que degrade no solo la calidad sensorial sino también la calidad física y química, por modificación de algunos compuestos. Aunque durante el almacenamiento de habichuelas y arvejas en estado congelado, con escaldado previo, no se ha visto regeneración de la actividad de POD, ${ }^{5,6}$ en ensayos de escaldado efectuados a extractos de esta enzima obtenidos de arveja se ha visto que ésta puede renaturalizarse, ${ }^{7}$ por lo tanto si la renaturalización se presenta, no se logrará el efecto deseado tras la aplicación del tratamiento térmico aplicado.

Si bien la POD ha sido estudiada en una gran cantidad de frutas y hortalizas no hay reportes de esta enzima en frutos de arazá. Para emplear la medida de la actividad de POD como criterio de grado de inactivación enzimática y como índice de calidad, es necesario desarrollar una metodología de extracción y cuantificación adecuada de POD, que permita obtener buenos resultados.

Es común encontrar reportes en los cuales se recomienda una extracción rápida de POD mediante la homogenización del tejido vegetal con agua en homogenizadores mecánicos, tipo Virtis, por 3 min, en los que el material es dispersado en el medio de extracción mediante cuchillas que pueden girar a velocidades entre $5.000 \mathrm{a}$ $30.000 \mathrm{rpm}$. Estos procedimientos se efectúan con la intención de obtener en corto tiempo el extracto enzimático y agilizar los experimentos requeridos para adquirir información acerca de la actividad de este tipo de enzimas. ${ }^{8}$ También, con el objetivo de retirar sustancias de carácter fenólico que pueden inhibir las enzimas en estudio, se recomienda el empleo de acetona previo a la extracción. ${ }^{8,9}$ De esta manera, se encuentra el empleo de la acetona con posterior extracción que puede ir desde unos pocos minutos hasta horas. Para la extracci- 
ón de la fracción soluble de POD se encuentra el uso de soluciones buffer, con valores de $\mathrm{pH}$ desde 6,0 hasta 7,5 de acetatos, fosfatos o Tris- $\mathrm{HCl}$, de concentraciones entre 10 a $200 \mathrm{mM}$. En algunos casos se emplea agua como medio de extracción. Las técnicas de medida, en general son espectrofotométricas y emplean $\mathrm{H}_{2} \mathrm{O}_{2}$ como sustrato y sustancias como ABTS [ácido 2,2'-azinobis(3-etilbenztiazol-6sulfónico], o-dianisidina, guayacol, p-fenilendiamina, entre otros, que actúan como donores de protones. La incubación de la mezcla de reacción se suele efectuar a valores de $\mathrm{pH}$ entre 5,0 a 6,5 y temperaturas entre 20 a $40{ }^{\circ} \mathrm{C}$. . $^{-12}$

El objetivo de este trabajo es seleccionar algunas condiciones durante la extracción y medida de actividad de POD. También se pretende evaluar la estabilidad térmica de la enzima al someter el extracto crudo a tratamientos térmicos, para luego determinar si se produce renaturalización de la POD durante su incubación posterior al escaldado.

\section{PARTE EXPERIMENTAL}

\section{Frutos de arazá}

Se adquirieron en mercados de la ciudad de Bogotá-Colombia, en estado maduro (100\% amarillo en corteza, olor característico intenso). Los frutos se despulparon de forma manual y la pulpa se homogenizó. Los experimentos se efectuaron siempre con pulpa recién procesada sin congelación previa.

\section{Extracción de peroxidasa}

Con base en las tendencias de extracción de la fracción soluble de POD, se ensayó el uso de dos extractantes diferentes, agua o buffer fosfatos $\mathrm{pH}$ 6,0. También se ensayaron extracciones rápidas o prolongadas y el uso de la técnica de precipitación de proteínas con acetona. Para desarrollar estos experimentos se puso en contacto $2 \mathrm{~g}$ de pulpa con $6 \mathrm{~mL}$ de agua o buffer fosfatos $50 \mathrm{mM} \mathrm{pH} 6,0$ por un tiempo determinado. Posteriormente, la suspensión fue centrifugada a $12000 \mathrm{rpm}$ durante $15 \mathrm{~min}$ y en el sobrenadante se efectuó la cuantificación de proteína y de actividad enzimática. En las diferentes etapas de extracción la temperatura no superó los $4{ }^{\circ} \mathrm{C}$.

En los procedimientos que involucraron el uso de acetona, se tomaron $2 \mathrm{~g}$ de pulpa y se maceraron en mortero con $6 \mathrm{~mL}$ de acetona a $-8{ }^{\circ} \mathrm{C}$. El líquido amarillo fue retirado por filtración. Este proceso se llevó a cabo dos veces. El residuo blanco fue puesto en contacto con $6 \mathrm{~mL}$ de agua o buffer fosfatos $50 \mathrm{mM}$ pH 6,0 y se continuó como se explicó en el párrafo anterior.

Se evaluó también el efecto del tiempo de extracción, a diferentes intervalos entre $30 \mathrm{~min}$ a $24 \mathrm{~h}$ y de la relación entre el volumen de extractante y el peso de pulpa empleado, desde 1 hasta $20 \mathrm{~mL}$ extractante/g pulpa.

\section{Medida de actividad}

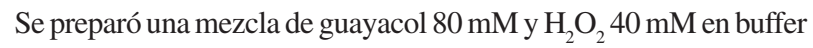
citratos $200 \mathrm{mM} \mathrm{pH}$ 5,5. $250 \mu \mathrm{L}$ de esta solución fueron transferidos a la celda de medida y se incubó a $25^{\circ} \mathrm{C}$. La reacción se inició por adición de $250 \mu \mathrm{L}$ del extracto enzimático crudo, incubado previamente durante 2 min a $25^{\circ} \mathrm{C}$. La concentración en la celda de medida de guayacol y $\mathrm{H}_{2} \mathrm{O}_{2}$ fue respectivamente 40 y $20 \mathrm{mM} .{ }^{9}$ Como resultado de la actividad de la POD sobre el guayacol se genera tetrahidroguayacol. Este producto de reacción fue medido por espectrofotometría a $470 \mathrm{~nm}$ cada 5 s durante 2 min. La velocidad se definió como el cambio en una unidad de absorbancia por s a las condiciones de cada ensayo y la actividad, como la velocidad por g de pulpa o por $100 \mathrm{~g}$ de pulpa.

Debido a que existen diversos factores que afectan la actividad enzimática, se evaluó el efecto del volumen de extracto enzimático, entre 50 a $250 \mu \mathrm{L}$; del $\mathrm{pH}$, entre 2,0 a 8,5 ; de la temperatura, entre 20 a $92{ }^{\circ} \mathrm{C}$; de la concentración de $\mathrm{H}_{2} \mathrm{O}_{2}$; entre 2 a $80 \mathrm{mM}$ y de guayacol, entre 2 a $160 \mathrm{mM}$. El pH de medida fue cambiado mediante el empleo de diferentes soluciones buffer, todas $200 \mathrm{mM}$ : gly- $\mathrm{HCl} \mathrm{pH} \mathrm{2,5,} \mathrm{citra-}$ tos $\mathrm{pH} 3,0$ a 5,5, fosfatos $\mathrm{pH} 6,0$ a 7,0 y Tris- $\mathrm{HCl} \mathrm{pH} 8,0$ a 9,0. ${ }^{9}$

\section{Medida de proteína}

Se empleó el método de Bradford linealizado. ${ }^{13}$ Se efectuaron curvas de calibración con BSA.

\section{Estabilidad térmica}

El extracto enzimático crudo fue incubado en baño de agua a 80 y $92{ }^{\circ} \mathrm{C}$ durante 0 a 5 min y se midió la actividad enzimática. Para evaluar la renaturalización, se eligieron los extractos previamente incubados a $80{ }^{\circ} \mathrm{C}$ durante 2 y $5 \mathrm{~min}$, se incubó a $25^{\circ} \mathrm{C}$ durante 0 a 24 h y se midió su actividad a diferentes intervalos de tiempo.

\section{Análisis de datos}

Los resultados de proteína son el promedio de tres determinaciones. Los resultados de actividad de POD son el promedio de seis determinaciones. Para evaluar el efecto de los tratamientos sobre las variables de respuesta se efectuaron los ANOVA y, para estimar si había diferencias estadísticas entre los promedios se efectuó la prueba de Tuckey.

\section{RESULTADOS Y DISCUSIÓN}

En la Tabla 1 se consignan los resultados de la cantidad de proteína extraída y de la actividad de POD tras la aplicación de diversos tratamientos de extracción. El ANOVA mostró que hubo efecto de los tratamientos de extracción sobre la proteína extraída $\left(\mathrm{p}=2,29 * 10^{-3}\right)$. De acuerdo a los resultados se puede evidenciar que aunque el

Tabla 1. Cantidad de proteína extraída y actividad de peroxidasa mediante el uso de diversas formas de extracción

\begin{tabular}{|c|c|c|}
\hline $\begin{array}{l}\text { Tratamiento de } \\
\text { extracción }\end{array}$ & $\begin{array}{l}\text { mg proteína/ } \\
\text { g pulpa }\end{array}$ & $\begin{array}{l}\text { Actividad POD } \\
(\Delta \mathrm{A} / \mathrm{s} / \mathrm{g} \text { pulpa })\end{array}$ \\
\hline 1. $A+$ Virtis $/ 3$ min & $3,05 \pm 1,56 a$ & $\mathrm{NC}$ \\
\hline $\begin{array}{l}\text { 2. A + Virtis } / 3 \mathrm{~min}+ \\
\text { Agitación } 1 \mathrm{~h}\end{array}$ & $2,10 \pm 0,35 \mathrm{a}$ & $\mathrm{NC}$ \\
\hline 3. $\mathrm{B}+\mathrm{Virtis} / 3 \mathrm{~min}$ & $1,65 \pm 0,24 b$ & $\mathrm{NC}$ \\
\hline $\begin{array}{l}\text { 4. } \mathrm{B}+\text { Virtis } / 3 \mathrm{~min}+ \\
\text { Agitación } 1 \mathrm{~h}\end{array}$ & $1,07 \pm 0,64 b c$ & $\mathrm{NC}$ \\
\hline $\begin{array}{l}\text { 5. Acetona }+\mathrm{A}+ \\
\text { Virtis/3 min }\end{array}$ & $0,76 \pm 0,17 \mathrm{c}$ & $\mathrm{NC}$ \\
\hline $\begin{array}{l}\text { 6. Acetona }+\mathrm{A}+ \\
\text { Agitación } 1 \mathrm{~h}\end{array}$ & $0,25 \pm 0,16 \mathrm{~d}$ & $\mathrm{NC}$ \\
\hline $\begin{array}{l}\text { 7. Acetona + B + } \\
\text { Virtis/3 min }\end{array}$ & $1,43 \pm 0,18 b$ & $1,01 \times 10^{-3} \pm 0,19 \times 10^{-3} \mathrm{~b}$ \\
\hline $\begin{array}{l}\text { 8. Acetona }+\mathrm{B}+ \\
\text { Agitación } 1 \mathrm{~h}\end{array}$ & $0,86 \pm 0,51 \mathrm{c}$ & $6,93 \times 10^{-3} \pm 2,62 \times 10^{-3} \mathrm{a}$ \\
\hline
\end{tabular}

A: Agua, B: Buffer fosfatos $50 \mathrm{mM}$ pH 6,0, NC: No cuantificable. Los resultados de proteína son el promedio de 3 medidas $\pm 1 \mathrm{SD}$ (desviación estándar). Los resultados de actividad de POD son el promedio de 6 medidas $\pm 1 \mathrm{SD}$. Letras diferentes indican diferencias significativas de acuerdo a la prueba de Tuckey, en proteína y de acuerdo a la prueba $t$ en actividad de POD. 
tratamiento de extracción rápido con agua mediante el empleo del homogenizador Virtis genera una alta extracción de proteína, no se detecta actividad de POD. Cuando las extracciones se efectúan sin tratamiento previo con acetona se obtienen mayores contenidos proteicos que cuando se emplea acetona dentro del proceso de extracción. Esto puede ser el resultado de la respuesta que suelen dar los polifenoles ante el reactivo de Bradford, que son retirados cuando se hace el tratamiento con acetona. En los tratamientos que emplearon precipitación de proteínas con acetona, se obtiene una mayor cantidad de proteína al extraer con buffer que cuando la extracción se hace con agua, resultado que está en relación con el incremento en la fuerza iónica que se logra al emplear el sistema buffer.

Tan sólo fueron efectivos dos tratamientos para obtener POD medible, en donde el uso de acetona y de buffer fue necesario para obtener la enzima activa. La prueba $t$ indica que los dos tratamientos tienen un efecto importante sobre la actividad de POD $\left(\mathrm{p}=1,91 * 10^{-3}\right)$. La agitación durante $1 \mathrm{~h}$ genera una respuesta 7 veces mayor en la actividad de POD que cuando se emplea el Virtis durante $3 \mathrm{~min}$. Se evidencia el papel importante de la precipitación de las proteínas con acetona, por lo que deben existir compuestos, principalmente fenoles, que inactivan la POD, que son separados de la fracción rica en proteínas mediante el empleo de la acetona. También se observa que el buffer fosfatos $50 \mathrm{mM} \mathrm{pH} 6$ se constituye en un mejor extractante de POD que el agua, probablemente como resultado de la fuerza iónica generada por el uso del buffer, que favorece la extracción de la enzima. En este sentido, se sabe que al usar sistemas de extracción con altas fuerzas iónicas, por ejemplo $\mathrm{NaCl} 1 \mathrm{M}$, no sólo se extrae la fracción soluble, sino también la iónica, ${ }^{14}$ por lo que es importante emplear un buffer de extracción de baja concentración para evitar la solubilización de las formas iónicas y trabajar con la fracción denominada soluble, que es la que puede entrar en contacto más fácilmente con los sustratos en la célula.

La Tabla 2 muestra los resultados de la evaluación del efecto del tiempo de agitación sobre la cantidad de proteína extraída y sobre la actividad de POD, respectivamente. El ANOVA mostró que hubo efecto del tiempo extracción sobre la proteína extraída $\left(\mathrm{p}=8,61 * 10^{-4}\right)$ y sobre la actividad enzimática $\left(\mathrm{p}=1,44^{*} 10^{-2}\right)$. Al incrementarse el tiempo de agitación se aumentó la extracción de proteína y con ello la actividad de POD. La tendencia observada indica que hubo una fácil solubilización de las proteínas y se requiere, de acuerdo a la prueba de Tuckey, $1 \mathrm{~h}$ para lograr el máximo de solubilidad de proteínas. A partir de ese tiempo no hubo cambio significativo en la cantidad de proteína soluble. Aunque la máxima actividad de POD se obtuvo luego de 24 h de extracción, a partir de las primeras $4 \mathrm{~h}$ el valor de actividad fue significativamente igual al obtenido a las $24 \mathrm{~h}$, por lo

Tabla 2. Efecto del tiempo de extracción sobre la cantidad de proteína extraída y actividad de peroxidada

\begin{tabular}{lcc}
\hline $\begin{array}{l}\text { Tiempo de } \\
\text { agitación }(\mathrm{h})\end{array}$ & $\begin{array}{c}\text { Proteína extraída } \\
(\mathrm{mg} / \mathrm{g} \text { pulpa })\end{array}$ & $\begin{array}{c}\text { Actividad de peroxidasa } \\
(\Delta \mathrm{A} / \mathrm{s} / 100 \mathrm{~g} \text { pulpa })\end{array}$ \\
\hline 0,5 & $4,13 \pm 0,44 \mathrm{~b}$ & $4,73 \pm 0,63 \mathrm{~b}$ \\
1 & $4,65 \pm 0,26 \mathrm{ab}$ & $4,68 \pm 0,48 \mathrm{~b}$ \\
2 & $4,72 \pm 0,14 \mathrm{ab}$ & $4,69 \pm 0,66 \mathrm{~b}$ \\
4 & $5,79 \pm 0,24 \mathrm{a}$ & $5,13 \pm 0,91 \mathrm{ab}$ \\
8 & $5,35 \pm 0,53 \mathrm{a}$ & $5,75 \pm 1,13 \mathrm{a}$ \\
12 & $5,51 \pm 0,21 \mathrm{a}$ & $5,52 \pm 0,70 \mathrm{ab}$ \\
24 & $5,81 \pm 0,69 \mathrm{a}$ & $5,94 \pm 0,39 \mathrm{a}$ \\
\hline
\end{tabular}

Los resultados de proteína son el promedio de 3 medidas \pm 1 SD (desviación estándar). Los resultados de actividad de POD son el promedio de 6 medidas $\pm 1 \mathrm{SD}$. Letras diferentes indican diferencias significativas de acuerdo a la prueba de Tuckey. que un tiempo de $4 \mathrm{~h}$ fue suficiente para efectuar la extracción.

Los resultados de la variación de la proteína extraída y de la actividad de POD por efecto de la variación entre la cantidad de buffer empleado para la extracción y la cantidad de pulpa se consignan en la Tabla 3. La variación de la relación pulpa/buffer marcó un efecto importante sobre la proteína extraída $\left(\mathrm{p}=3,12^{*} 10^{-8}\right)$ y sobre la actividad de POD $\left(\mathrm{p}=2,19^{*} 10^{-6}\right)$. Al incrementar la relación entre la cantidad de buffer usado para la extracción y la masa de pulpa se obtuvo una mayor extracción de proteína. Sin embargo, la actividad enzimática, referida a g de pulpa, disminuyó drásticamente cuando se pasó de una relación buffer/pulpa de 5/1 a 10/1. Como en estos ensayos de medida de actividad siempre se puso la misma cantidad de extracto enzimático $(250 \mu \mathrm{L})$, a medida que se ampliaba la relación buffer/ pulpa, aunque en total se extraía más proteína, la concentración era menor, por lo que se ponía menor cantidad de proteína. Si la proporción de enzima extraída, dentro de la proteína total, es siempre la misma, se esperaría mayor actividad referida a g de pulpa conforme se aumentaba el volumen del buffer de extracción, en la misma manera como se obtuvo mayor extracción de proteína. El descenso en la actividad podría estar relacionado con la presencia de un inhibidor en los reactivos usados para medir la actividad. Esto se verifica en la Figura 1a, en la que se aprecia que aunque hay una relación directa entre el volumen de extracto enzimático y la velocidad enzimática (absorbancia por unidad de tiempo) $\left(\mathrm{p}=9,98 * 10^{-10}\right)$, se requiere de cierto volumen para iniciar la actividad, por lo que efectivamente hubo un inhibidor en alguno de los reactivos empleados. Como resultado, la actividad referida a g de pulpa se vio afectada por el volumen de enzima empleado $\left(\mathrm{p}=2,06 * 10^{-3}\right)$ y disminuyó de manera significativa por debajo de $150 \mu \mathrm{L}$ de extracto enzimático (Figura 1b). Aunque se ensayaron diversas fuentes comerciales de reactivos, siempre se encontró ese efecto inhibidor.

Tabla 3. Efecto de la relación buffer de extracción a pulpa sobre la cantidad de proteína extraída y actividad de peroxidada

\begin{tabular}{lcc}
\hline $\begin{array}{l}\text { Relación buffer/ } \\
\text { pulpa }(\mathrm{mL} / \mathrm{g})\end{array}$ & $\begin{array}{c}\text { Proteína extraída } \\
(\mathrm{mg} / \mathrm{g} \text { pulpa })\end{array}$ & $\begin{array}{c}\text { Actividad de peroxidasa } \\
(\Delta \mathrm{A} / \mathrm{s} / 100 \mathrm{~g} \text { pulpa })\end{array}$ \\
\hline 1 & $2,57 \pm 0,70 \mathrm{~d}$ & $5,07 \pm 0,70 \mathrm{a}$ \\
3 & $1,40 \pm 0,39 \mathrm{e}$ & $5,39 \pm 0,39 \mathrm{a}$ \\
5 & $3,76 \pm 0,35 \mathrm{c}$ & $5,55 \pm 0,35 \mathrm{a}$ \\
10 & $6,01 \pm 0,56 \mathrm{~b}$ & $1,78 \pm 0,56 \mathrm{~b}$ \\
20 & $10,60 \pm 0,85^{\mathrm{a}}$ & $0,61 \pm 0,08 \mathrm{~b}$ \\
\hline
\end{tabular}

Los resultados de proteína son el promedio de 3 medidas \pm 1 SD (desviación estándar). Los resultados de actividad de POD son el promedio de 6 medidas $\pm 1 \mathrm{SD}$. Letras diferentes indican diferencias significativas de acuerdo a la prueba de Tuckey.

De acuerdo a la Figura 1c se obtuvo una alta respuesta de POD a valores de $\mathrm{pH}$ comprendidos entre 5,0 hasta 6,5. Estos valores están en el intervalo de los encontrados para esta misma enzima extraída de la corteza de pitaya amarilla (Acanthocereus pitajaya): 5,0 a 5,5, ${ }^{9}$ de repollo (Brassica oleracea): 6,4, ${ }^{11}$ del conjunto pulpa más corteza de uva caimarona (Pourouma cecropiifolia): $6,0,{ }^{15}$ de la pulpa de uva caimarona: $6,0,{ }^{16} \mathrm{y}$ de los encontrados para tres isoPOD de arveja (Pisum sativum): 5,0, 6,0 y 5,0.7

El intervalo de temperatura en el que se obtuvo una máxima actividad enzimática estuvo entre 60 a $75{ }^{\circ} \mathrm{C}$ (Figura $1 \mathrm{~d}$ ), valores superiores al reportado para POD extraída de corteza de pitaya amarilla: 20 a $25^{\circ} \mathrm{C},{ }^{9}$ de repollo: $45^{\circ} \mathrm{C},{ }^{11}$ de uva caimarona (corteza más pulpa), en el que la actividad enzimática es mejor entre 30 a $40{ }^{\circ} \mathrm{C},{ }^{15}$ y de pulpa de uva caimarona: $37^{\circ} \mathrm{C} . .^{16}$

Cuando se evaluó el efecto de la concentración de $\mathrm{H}_{2} \mathrm{O}_{2}$ y del guayacol sobre la actividad de POD (Figuras 2e y 2f) se obtuvo un 

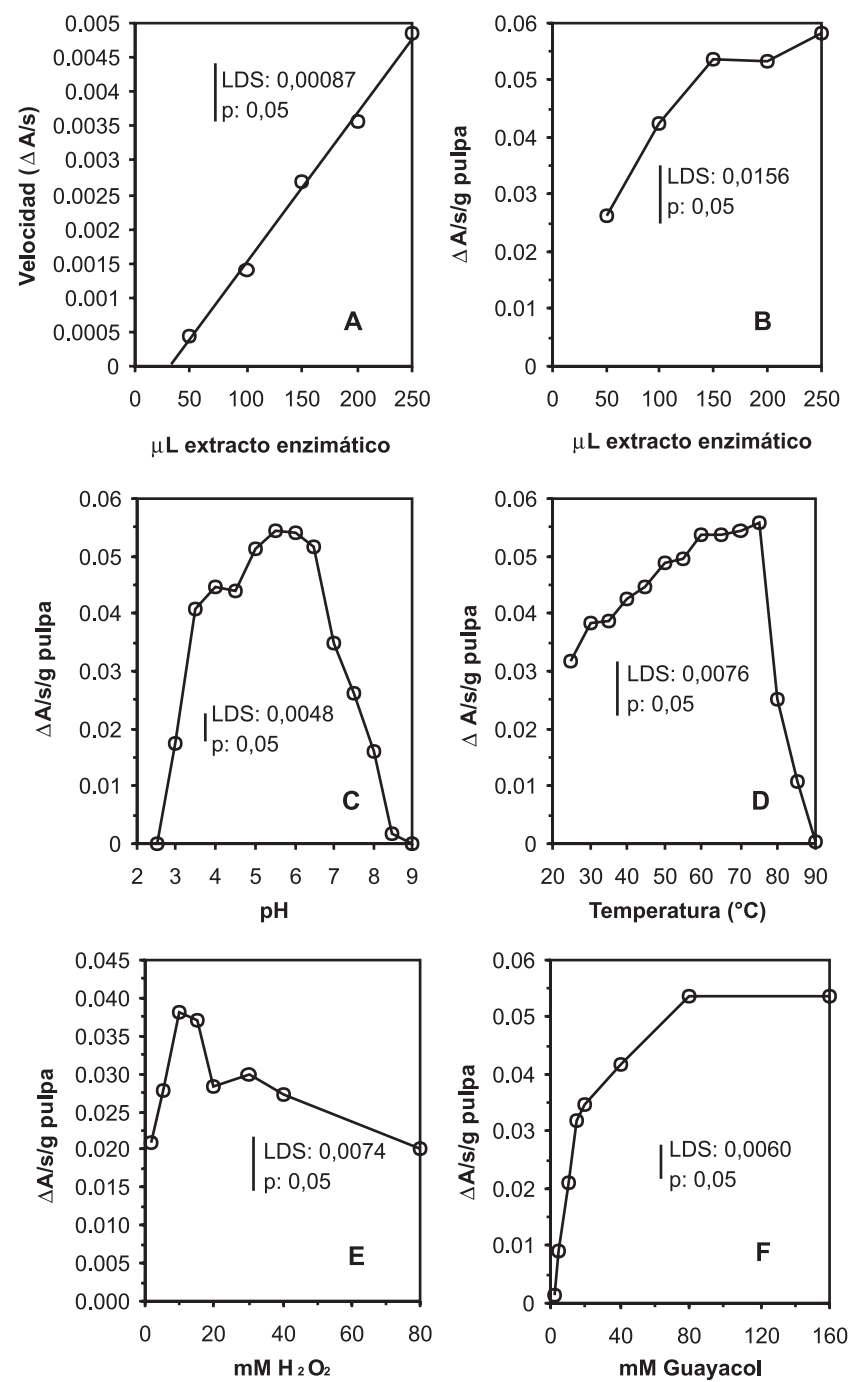

La barra representa el valor estadístico (LDS) para comparar los promedios, de acuerdo a la prueba de Tuckey; por lo que no es necesario ubicar la desviación estándar de cada promedio. Si las diferencias entre dos promedios son mayores al LDS, entonces habrá diferencia a un $\alpha$ de 0,05

Figura 1. Efecto A. y B. del volumen de extracto enzimático sobre la velocidad y la actividad de POD, C. del pH, D. de la temperatura de incubación, E. de la concentración de $\mathrm{H}_{2} \mathrm{O}_{2}$ y $\mathrm{F}$. de la concentración de guayacol sobre la actividad de peroxidasa

valor máximo de actividad a $15 \mathrm{mM}$ de $\mathrm{H}_{2} \mathrm{O}_{2}$ y $80 \mathrm{mM}$ de guayacol. A valores superiores a $15 \mathrm{mM}$ de $\mathrm{H}_{2} \mathrm{O}_{2}$ hubo inhibición en la actividad enzimática. Aunque la POD aquí estudiada manifestó alta tolerancia al guayacol existen reportes en los que se muestra que el guayacol puede llegar a inhibir esta enzima. Así, para una iso-POD de arveja se indica que su actividad se inhibe a concentraciones de guayacol superiores a $24 \mathrm{mM}$ y para otras dos iso-POD la inhibición se da a valores mayores a 40 mM. ${ }^{7}$ De otro lado, el efecto inhibidor de $\mathrm{H}_{2} \mathrm{O}_{2}$ sobre la actividad de POD encontrado en este trabajo ha sido descrito en otros reportes y puede estar relacionado con el efecto oxidante de este compuesto sobre algunos aminoácidos del sitio activo. ${ }^{7,9} 16$ Para POD extraída de corteza de pitaya amarilla se reporta inhibición en su actividad por encima de $40 \mathrm{mM}$ de $\mathrm{H}_{2} \mathrm{O}_{2} .{ }^{9}$ En un ensayo de purificación de POD de arveja se encontró que las isoenzimas son inactivadas a concentraciones de $\mathrm{H}_{2} \mathrm{O}_{2}$ por encima de 24 y $32 \mathrm{mM}$, dependiendo de la iso-POD. ${ }^{7}$

La inactivación térmica de POD (Figura 2a) siguió una cinética de tipo logarítmico y hubo una relación directa entre las dos temperaturas estudiadas y el grado de inactivación. De acuerdo a la linealización, se requiere un tiempo de $32 \mathrm{~s}$ para disminuir la actividad a un $10 \%$ de la inicial cuando los extractos son calentados a $92{ }^{\circ} \mathrm{C}$. Cuando este tratamiento se efectúa a $80{ }^{\circ} \mathrm{C}$ el tiempo para lograr el mismo efecto es de 1,9 $\min (1 \mathrm{~min}, 54 \mathrm{~s}$ ).

En la Figura $2 \mathrm{~b}$ se observa que el extracto que fue tratado durante 2 min a $80{ }^{\circ} \mathrm{C}$ recuperó parcialmente su actividad durante las primeras 2 h de incubación a $25^{\circ} \mathrm{C}$ y hacia las 20 h su actividad bajó a niveles no detectables. Cuando el extracto se calentó a $80^{\circ} \mathrm{C}$ durante 5 min, aunque la inactivación fue total, la enzima recuperó parte de su actividad, si bien la recuperación de actividad fue menor que la lograda en el tratamiento anterior. La tendencia a la reactivación en soluciones modelo ha sido reportada por otros autores. ${ }^{7}$

Si bien se espera que al inactivar completamente la POD, las otras enzimas también lo hayan sido y que la tendencia a la reactivación sea menor, algunos trabajos sugieren que es mejor efectuar tratamientos en donde se disminuya la actividad hasta un $10 \%$ de la inicial, con lo que se logra no sólo una buena inactivación sino que también se espera que el tratamiento térmico no vaya en detrimento de los componentes nutricionales, de las características físicas y sensoriales que suelen ser negativamente afectadas por el uso de tratamientos térmicos prolongados. El tratamiento térmico deberá ser suficiente para estabilizar la calidad de la pulpa y al mismo tiempo que las pérdidas netas al final del almacenamiento congelado generen un producto de mejor calidad si se compara con aquel al cual no se le efectuó ningún tratamiento térmico previo a la congelación.
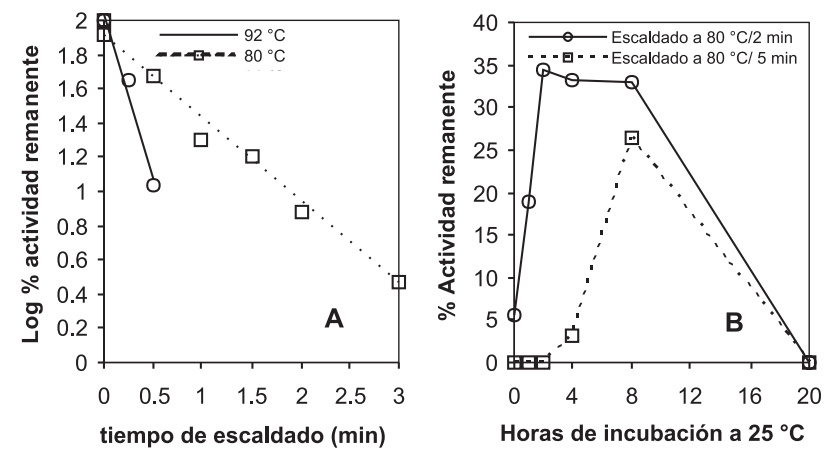

$\left(\operatorname{LDS}_{92} \circ^{\circ}: 0,0910, \operatorname{LDS}_{80}{ }^{\circ} \mathrm{c}: 0,0068 \mathrm{p}: 0,05\right)$. El valor estadístico LDS se emplea para comparar los promedios, de acuerdo a la prueba de Tuckey; por lo que no es necesario ubicar la desviación estándar de cada promedio. Si las diferencias entre dos promedios son mayores al LDS, entonces habrá diferencia a un $\alpha$ de 0,05

Figura 2. a. Inactivación térmica (Los coeficientes de correlación obtenidos son significativos) y b. reactivación de POD por incubación a $25^{\circ} \mathrm{C}$

\section{CONCLUSIONES}

Se encontró que para la extracción de POD de pulpa de arazá es necesaria la precipitación previa de proteínas con acetona. La extracción de la fracción soluble se hace completa luego de 4 h de agitación a $4{ }^{\circ} \mathrm{C}$ con buffer fosfato de sodio $50 \mathrm{mM} \mathrm{pH} \mathrm{6,0.} \mathrm{Se} \mathrm{pueden} \mathrm{emplear} \mathrm{entre} 1$ a $5 \mathrm{~mL}$ de buffer de extracción por cada g pulpa. Puesto que se encontró evidencia de inhibidores en los reactivos para la medida de actividad, se recomienda el empleo de al menos $150 \mu \mathrm{L}$ del extracto en las condiciones de ensayo. Además, la medida se puede efectuar a valores de $\mathrm{pH}$ entre 5,0 a 6,5, temperaturas entre 60 a $75^{\circ} \mathrm{C}$, concentración de $\mathrm{H}_{2} \mathrm{O}_{2}$ de 10 a 15 mM y guayacol entre 80 a $160 \mathrm{mM}$. Aunque se observó que los extractos inactivados por tratamiento con calor pueden recuperar parcialmente su actividad durante la incubación a $25^{\circ} \mathrm{C}$, en algunos trabajos se ha encontrado que la tendencia a la reactivación después del tratamiento térmico no ocurre, como resultado del almacenamiento a temperaturas de congelación que disminuye la tendencia a la renaturalización.,56 


\section{REFERENCIAS}

1. Hernández, M. S.; Tesis doctorado, Universidad Nacional de Colombia, Colombia, 2001.

2. Narváez, C. E.; Revista Colombiana de Química 2003, 32, 93.

3. Mejía, H. L. J.; Restrepo, S. L. P.; Narváez, C. C. E.; Agronomía Colombiana 2006, 24, 875.

4. Millán, B. E.; Narváez, C. C. E.; Restrepo, S. L. P.; Agronomía Colombiana 2007, 25, 333.

5. Bahçeci, K. S.; Serpen, A.; Gôkmen, V.; Acar, J. N.; J. Food Engineering 2005, 66, 187

6. Gökmen, V.; Bahçeci, K. S.; Serpen, A.; Acar, J. N.; LWT - Food Sci. Technol. 2005, 38, 903

7. Halpin, B.; Pressey, R.; Jen, J.; Mondy, N.; J. Food Sci. 1989, 54, 644.
8. Marín, M. A.; Cano, M. P.; J. Food Sci. 1992, 57, 690

9. Baquero, D. L. E.; Castro, R. J. A.; Narváez, C. C. E.; Revista Colombiana de Química 2006, 35, 91.

10. Duarte-Vázquez, M. A.; García-Almendárez, B.; Regalado, C.; Whitaker, J. R.; J. Agric. Food Chem. 2000, 48, 1574.

11. Fujita, S.; Bin-Saari, N.; Maegawa, M.; Tetsuka, T.; Hayashi, N.; Tono, T.; J. Agric. Food Chem. 1995, 43, 1138.

12. Préstamo, G.; Manzano, P.; HortScience 1993, 28, 48.

13. Zor, T.; Sellinger, Z.; Anal. Biochem. 1996, 236, 302.

14. Grison, R.; Pilet, P. E.; J. Plant Physiol. 1984, 118, 189.

15. Narváez, C. C. E.; Restrepo, P.; Revista Colombiana de Química 2002, $31,131$.

16. Rivera, C. A. P.; Restrepo, P.; Narváez, C. C. E.; Revista Colombiana de Química 2004, 33, 57. 